\title{
Acute abdomen as a consequence of an unusual suicide attempt: intra-abdominal injection of sulfuric acid
}

This article was published in the following Dove Press journal:

International Medical Case Reports Journal

4 November 2016

Number of times this article has been viewed

\author{
Anna Lepore' \\ Davide D'Antini' \\ Pasquale Raimondo² \\ Lucia Mirabella' \\ Leonardo Pennisi' \\ Giuseppe Carrillo' \\ Antonella Cotoia' \\ Michele Dambrosio' \\ Gilda Cinnella' \\ 'Department of Anesthesia and \\ Intensive Care, University of Foggia, \\ Viale Pinto, Foggia, ${ }^{2}$ Department of \\ Anesthesia and Intensive Care, "Santa \\ Maria" Hospital,Via De Ferrariis, \\ Bari, Italy
}

\begin{abstract}
Caustic ingestion is a common cause of life-threatening upper gastrointestinal tract injuries. It mostly happens in children as accidental exposure, but may occur in adults as a result of suicide attempt. We present a case of an acute abdomen that occurred after a peculiar way of self-administration of sulfuric acid as a suicide attempt in an adult psychiatric male patient, already known for self-harm with caustic agents in the previous years. In a few hours, the patient developed diffuse peritonitis, pneumoperitoneum, and a rapid hemodynamic deterioration, as a consequence of ileum and sigmoid necrosis, requiring an emergency surgery with the application of a damage control strategy. The patient was then transferred to intensive care unit for hemodynamic stabilization, and definitive surgical correction of the abdominal lesions was performed after 3 days with Hartmann procedure. Thirty-nine days after hospital admission, the patient was discharged. In conclusion, to our knowledge, never has been reported in the literature a case of intra-abdominal self-administration of caustic substance causing a rapid evolution of clinical conditions and requiring the application of damage control strategy.
\end{abstract}

Keywords: abdomen, acute, caustics, sulfuric acid, suicide, attempted, peritonitis, laparotomy

\section{Introduction}

Worldwide, caustic injuries mostly occur in pediatric patients, as it is estimated that $80 \%$ of cases are accidental ingestion of household cleaning products in children. ${ }^{1-3}$

Caustic agents poisoning among adults is less frequent and is commonly intentional rather than accidental, as suicidal attempts by ingestion, that causes serious damage to oral mucous membrane, lips, and tongue, as well as esophagus and stomach. ${ }^{4-6}$

Most of the cases in which the intent is to commit suicide include teens and young adults in their 20s, and psychiatric and alcoholic patients. ${ }^{7,8}$

We present a peculiar case of caustic poisoning in an adult psychiatric male patient who deliberately self-administered an intra-abdominal injection of concentrated sulfuric acid for suicidal purposes, thus developing diffuse peritonitis and subsequently had to be surgically treated and admitted to our intensive care unit.

The publication of this clinical case report was approved by the Institutional Review Board of the University Hospital "Riuniti" of Foggia. Upon discharge from the psychiatric ward, the patient and his family reviewed the case report and gave written informed consent to publish the report.

\section{Case description}

A 37-year-old man was evaluated in the emergency department of the University Hospital of Foggia, Italy, for a suicide attempt by intra-abdominal injection of a caustic
Correspondence: Davide D'Antini Department of Anesthesia and Intensive Care, University of Foggia, Viale Pinto I. Foggia 7I 100, Italy

Tel +39088I 732307

Fax +390881732387

Email davide.dantini@unifg.it 
agent under the influence of drugs. The patient had a medical history of psychiatric disorder and drug abuse. This event was preceded 3 years before by deliberate ingestion of a household chemical (hydrochloric acid) with the intent of committing suicide. The patient underwent total gastrectomy, subtotal esophagectomy, and reconstruction of the jejunum.

At arrival, the patient was fully conscious, agitated, and complained of abdominal pain. Initial evaluation by the emergency room physician revealed mild tachypnea (respiratory rate of 22 breaths/min), saturation of $98 \%$ under room air, $100 / 60 \mathrm{mmHg}$ arterial blood pressure, heart rate of 98 beats per minute, and $36.5^{\circ} \mathrm{C}$ body temperature.

Initial blood gas analysis showed $\mathrm{pH} 7.19$, bicarbonate levels $13.4 \mathrm{mEq} / \mathrm{L}, \mathrm{PaCO} 2$ level $35 \mathrm{mmHg}$, and anion gap of $26 \mathrm{mEq} / \mathrm{L}$, so bicarbonate infusion was started while the patient was transferred to the emergency surgery department for further evaluation. The remaining initial biochemistry showed normal values, except for positive tests for cocaine and benzodiazepines.

On physical examination, the patient presented clear signs of acute abdomen with three visible different injection sites: left iliac fossa, mesogastrium, and hypogastrium.

Computerized tomography scan showed "marked pneumoperitoneum and discreet intra-abdominal free fluid, more significant in the upper quadrants with air-fluid level in the right upper quadrant" (Figure 1).

Due to hemodynamic deterioration (blood pressure $70 / 40 \mathrm{mmHg}$, heart rate 130 beats per minute), the patient underwent emergency surgery of a damage control laparotomy: ileal and sigmoid resection was performed due to widespread peritonitis and necrosis of the ileum and sigmoid.

On arrival at the operating room, the anesthesiologist placed two peripheral intravenous catheters and a radial catheter for continuous blood pressure monitoring and blood gas analyses. During the procedure, heated intravenous fluids, two fresh frozen plasma, and one pack red blood cell units were infused in order to manage intraoperative anemia (hematocrit $21 \%$ and hemoglobin $7 \mathrm{~g} / \mathrm{dL}$ ) and a contextual alteration of coagulation as documented by viscoelastic test executed during surgery. Furthermore, a warming mattress was positioned to prevent hypothermia.

Upon arrival of the patient at intensive care, the treatment focused on normothermia, tissue perfusion, appropriate values of hemoglobin (target 70-90 g/L Hb), and coagulation profile maintenance (prothrombin time/partial thromboplastin time $<1.5 \cdot$ normal; fibrinogen $>1.5-2.0 \mathrm{~g} / \mathrm{L}$ ) while monitoring intra-abdominal pressure (intravesicular pressure monitoring) to prevent abdominal compartment syndrome.

Definitive surgical correction of the lesions was performed at day 3 from the self-harming event: the "second look" consisted in peritoneal toilet, ileal recanalization, and terminal colostomy (Hartmann procedure).

Histology confirmed coagulative necrosis of examined tissues, full thickness, much more represented on the serosa than the mucosa, with thrombosis of small vessels, the presence
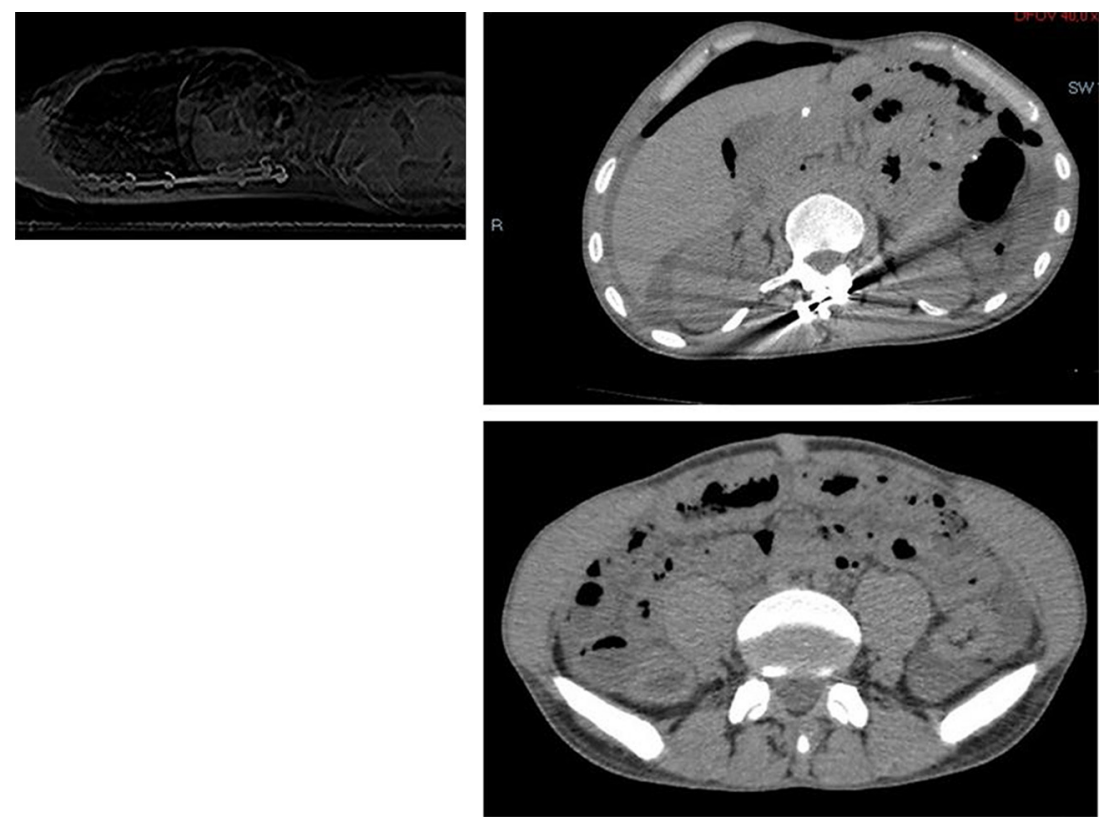

Figure I Computerized tomography scan showing the presence of marked pneumoperitoneum and discreet intra-abdominal free fluid, more evident in the upper quadrants, with air-fluid level in the right upper quadrant. 
of granulation tissue, hyperemic mucositis and, in some sections, mucosal discoloration.

The patient was discharged from the intensive care unit on day 6 and transferred to emergency surgery department since intensive treatment was no longer required.

Twenty-five days after admission, the patient was transferred to the psychiatric ward and then discharged after another 2 weeks of hospitalization.

\section{Discussion}

This is, to our knowledge, the first report of intra-abdominal injections of sulfuric acid.

Sulfuric acid is a colorless, odorless oily liquid; it is soluble in water with release of heat. It is highly corrosive to metals and tissues and is widely used as toilet bowl and drain cleaner.

In the literature, few cases of sulfuric acid drain cleaner ingestion and its consequences are described. ${ }^{5}$

Caustic agent ingestion can cause severe damage to oral mucous membrane, lips, and tongue, and, above all, to the esophagus and stomach. ${ }^{9-11}$

The most common caustic-related injury due to ingestion of chemical agents is corrosive esophagitis; in the US, ingestion of acid substances responsible for caustic injury is less frequently reported than the ingestion of alkaline agents, ${ }^{1}$ such as detergents, cleaning products, and bleaches. On the other hand, the corrosive esophagitis acidic-agent related is characterized by higher rates of complications, such as stricture and perforation, in comparison with alkaline-agent ingestion. ${ }^{11}$

Alkaline agents cause liquefaction necrosis, which, in a short span of time leads to mucosal destruction, and in 1 or 2 days, the damage caused to the mucosa is exacerbated by thrombosis of small vessels. The lytic action on tissues is particularly destructive. ${ }^{12}$ Acidic agents, in contrast, cause coagulation necrosis with eschar formation and, in some cases, limited tissue penetration. ${ }^{1}$

The intensity of destruction depends on various factors: type, concentration, time of contact, and amount of the ingested substance. ${ }^{9,13}$

In contrast to children, whose poisoning is mainly accidental, a suicide attempt is the usual cause of caustic ingestion in adults, especially among teens, and psychiatric and alcoholic patients. ${ }^{7,8}$

While in Western countries alkaline agents are responsible for the majority of caustic-related injuries, ingestion of acidic agents is more common in India due to the wider availability among lower socio-economic groups. ${ }^{12-14}$

Our patient had already attempted suicide 3 years ago by ingesting hydrochloric acid, which resulted in total gastrectomy and subtotal esophagectomy due to necrosis of the stomach and distal esophagus, and had undergone subsequent surgical reconstruction.

The patient, while undergoing psychiatric treatment for his bipolar disorder, attempted suicide again, and the way of self-administration of the caustic is peculiar and never mentioned in the literature: intra-abdominal injection of concentrated sulfuric acid, an easily available cleaning product.

While the caustic ingestion first causes damage on the mucous membrane of the gastrointestinal tract and thereafter perforation may occur, in our patient's particular way of administration led to immediate coagulation necrosis of the intestinal peritoneum, with widespread peritonitis and intestinal necrosis. The acute abdomen required emergent surgical treatment, which consisted of a damage control laparotomy, ${ }^{15}$ followed by recovery in the intensive care unit and then a second surgery for definitive damage correction.

The strategy of the damage control laparotomy is applied to patients with severely impaired physiological reserve induced by the trauma. The rationale of the strategy is to quickly check the conditions at risk for survival, perform an abbreviated laparotomy to control the gastrointestinal damage, and delay the definitive correction of the lesions while the patient is admitted and treated in intensive care; only when the lethal triad of hypothermia, metabolic acidosis, and coagulopathy is corrected, the patient may subsequently undergo definitive surgery. ${ }^{15,16}$

Along with the surgical strategy of temporization, damage control resuscitation had to be applied to limit the physiological derangement of the patient due to both caustic injury and surgery itself. ${ }^{16,17}$

The treatment focused on normothermia, tissue perfusion, appropriate values of hemoglobin, and coagulation profile maintenance while monitoring intra-abdominal pressure to prevent abdominal compartment syndrome. Physiological and biochemical stabilization was achieved by appropriate vital signs monitoring, frequent blood tests to evaluate organ functions, mechanical ventilation, hemodynamic monitoring, and electrolyte and acid-base balance correction.

In conclusion, this case is paradigmatic of the importance of cooperation between the different figures involved: the emergency room physician, the toxicologist, the surgeon, the anesthesiologist, the resuscitator; their prompt coordination allowed rescue of the patient and the successful outcome.

\section{Disclosure}

The authors report no conflicts of interest in this work. 


\section{References}

1. Ramasamy K, Gumaste VV. Corrosive ingestion in adults. J Clin Gastroenterol. 2003;37(2):119-124.

2. Beirens TM, van Beeck EF, Dekker R, Brug J, Raat H. Unsafe storage of poisons in homes with toddlers. Accid Anal Prev. 2006;38(4): $772-776$.

3. McKenzie LB, Ahir N, Stolz U, Nelson NG. Household cleaning product-related injuries treated in US emergency departments in 1990-2006. Pediatrics. 2010;126(3):509-516.

4. Goldman LP, Weigert JM. Corrosive substance ingestion: a review. Am J Gastroenterol. 1984;79(2):85-90.

5. Matshes EW, Taylor KA, Rao VJ. Sulfuric acid injury. Am J Forensic Med Pathol. 2008;29(4):340-345.

6. Park KS. Evaluation and management of caustic injuries from ingestion of acid or alkaline substances. Clin Endos. 2014;47(4): 301-307.

7. Wu MH, Lai WW. Esophageal reconstruction for esophageal strictures or resection after corrosive injury. Ann Thorac Surg. 1992;53(5): 798-802.

8. Rollin M, Jaulim A, Vaz F, Sandhu G, Wood S, Birchall M, Dawas K. Caustic ingestion injury of the upper aerodigestive tract in adults. Ann $R$ Coll Surg Engl. 2015;97(4):304-307.
9. Mamede RC, de Mello Filho FV. Ingestion of caustic substances and its complications. Sao Paulo Med J. 2001;119(1):10-15.

10. Gupta SK, Rana AS, Gupta D, Jain G, Kalra P. Unusual presentation of caustic ingestion and its surgical treatment: a case report. J Maxillofac Oral Surg. 2011;10(1):74-76.

11. Poley JW, Steyerberg EW, Kuipers EJ, et al. Ingestion of acid and alkaline agents: outcome and prognostic value of early upper endoscopy. Gastrointest Endosc. 2004;60(3):372-377.

12. Rajabi MT, Maddah G, Bagheri R, Mehrabi M, Shabahang H, Lorestani F. Corrosive injury of the upper gastrointestinal tract: review of surgical management and outcome in 14 adult cases. Iran J Otorhinolaryngol. 2015;27(78):15-21.

13. Lahoti D, Broor SL. Corrosive injury to the upper gastrointestinal tract. Indian J Gastroenterol. 1993;12(4):135-141.

14. Hugh TB, Kelly MD. Corrosive ingestion and the surgeon. JAm Coll Surg. 1999;189(5):508-522.

15. Lee JC, Peitzman AB. Damage-control laparotomy. Curr Opin Crit Care. 2006;12(4):346-350.

16. Midwinter MJ. Damage control surgery in the era of damage control resuscitation. J R Army Med Corps. 2009;155(4):323-326.

17. Lamb CM, MacGoey P, Navarro AP, Brooks AJ. Damage control surgery in the era of damage control resuscitation. Br J Anaesth. 2014;113(2): $242-249$.
International Medical Case Reports Journal

\section{Publish your work in this journal}

The International Medical Case Reports Journal is an international, peer-reviewed open-access journal publishing original case reports from all medical specialties. Previously unpublished medical posters are also accepted relating to any area of clinical or preclinical science. Submissions should not normally exceed 2,000 words or
Dovepress

4 published pages including figures, diagrams and references. The manuscript management system is completely online and includes a very quick and fair peer-review system, which is all easy to use. Visit http://www.dovepress.com/testimonials.php to read real quotes from published authors.

Submit your manuscript here: https://www.dovepress.com/international-medical-case-reports-journal-journal 